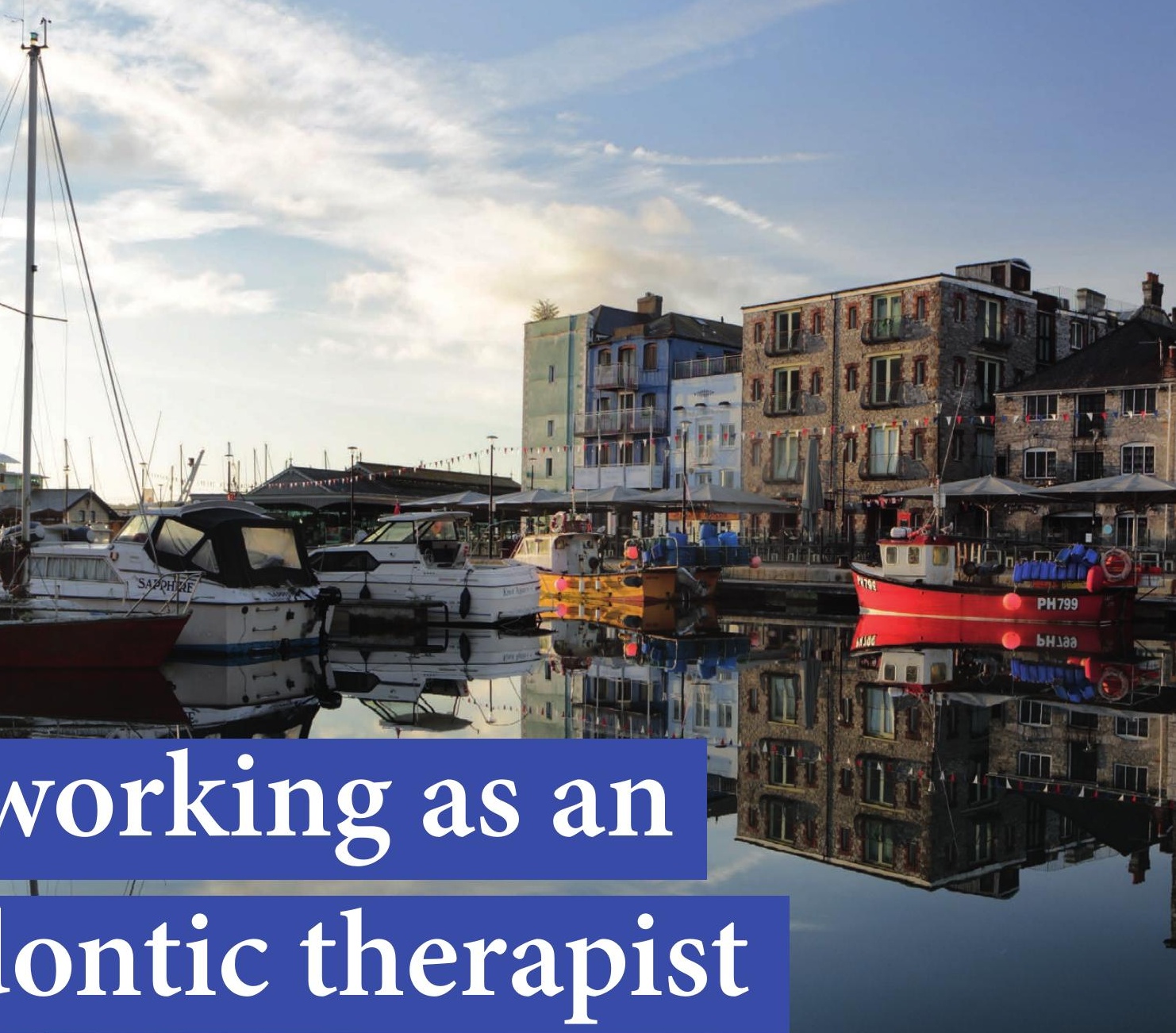

\title{
so satisfying'
}

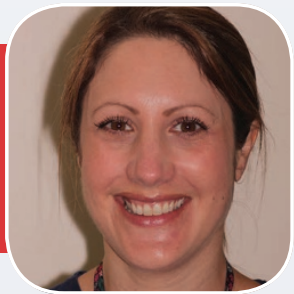

Amanda Stephens, 38, is an orthodontic therapist at Plymouth Hospitals NHS Trust. She is married to lan, a photographer, and they have two daughters.

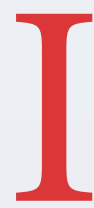

have always lived in Plymouth, although now I live in a small village just outside of Plymouth. I usually get up at 6.15 am and grab some toast while getting my daughters ready for school. I drive to work which is about seven miles away, and work 8.30 am to $5 \mathrm{pm}$ four days a week.

I do morning and afternoon clinics except for an admin session on a Monday afternoon. I work in a busy hospital department with a huge variety of staff. In the orthodontic department there are consultants, registrars and associate specialists as well as a highly skilled nursing team and a dental hygienist. However, I am also involved in multidisciplinary clinics where patients are seen jointly with the maxillofacial, restorative and visiting cleft teams. We are also lucky enough to have a dedicated dental radiography department and an on-site dental laboratory with both dental and maxillofacial dental technicians.

Working in a hospital I only see NHS patients and therefore most of my patients are children and teenagers. However, they tend to be the more complicated patients with either a challenging malocclusion that needs careful planning by a consultant orthodontist, or those with a complex medical history. We do treat some adult patients who generally undergo orthodontics and orthognathic surgery in order to treat functional malocclusions. We also run regular clinics for patients with cleft lip and/or palate and these patients are seen jointly with the specialist team from Bristol.

I find working as an orthodontic therapist so satisfying and really enjoy my job. I see my patients every six to eight weeks over a period of about two years and during that time I find that I can really build a great relationship with the patient and their family. Orthodontics is often the first time many children will experience anyone working in their mouth and on their teeth. I like to think that I can offer a gentle introduction to dentistry, as well as offering oral hygiene and diet advice that will help that child develop good habits to keep their teeth healthy throughout their life.

Seeing a child grow in confidence as their teeth straighten is so rewarding and nothing beats the sight of a beaming child (or adult!) on the day that their brace is removed and their beautiful smile is revealed.

When I was at school I wanted to be a veterinary nurse, but I started working as a receptionist in a dental practice. I always thought that the dental nurses had a much more interesting job than me! The practice 


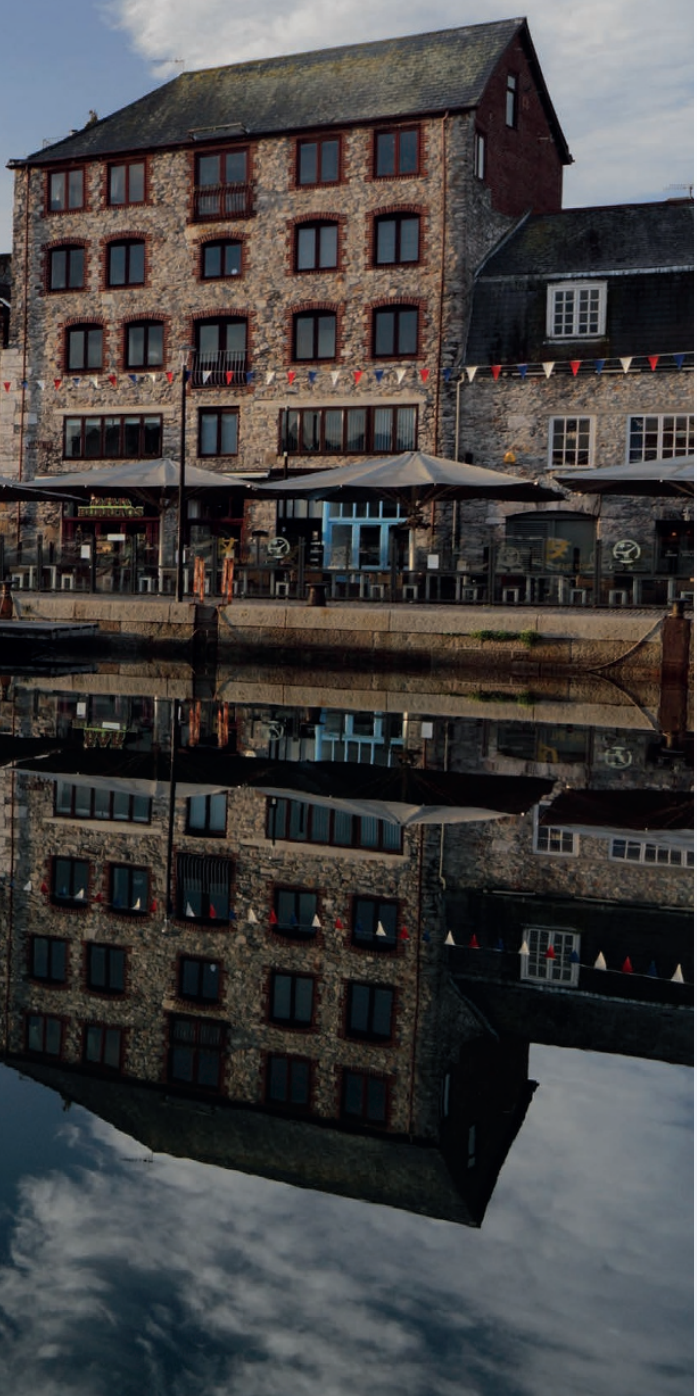

was newly opened and still growing; when the principal dentist wanted to advertise for a new dental nurse, I asked him if he would employ me and allow me to train as a dental nurse.

He agreed, giving me a two month trial, and I never looked back!

I worked at that first practice for six years gaining my NEBDN National Certificate in Dental Nursing in November 2005. I then took a job in the Orthodontic Department at Derriford Hospital in Plymouth in 2007. I had never been involved with orthodontics before so the first few months were a steep learning curve, but I found it fascinating. I took the NEBDN post qualification Certificate in Orthodontic Nursing in 2012 and the Certificate in Oral Health Education in 2014. I had by this time set my heart on becoming an orthodontic therapist.

Fortunately, at the end of 2014, the department decided to create a post for its first ever orthodontic therapist and after a rigorous selection day I was thrilled to gain the position of Trainee Orthodontic Therapist and started my new role in January 2015. After a year of hard work, in December 2015 I obtained my Diploma in Orthodontic Therapy RCSEd and started working at
Derriford Hospital as a fully qualified orthodontic therapist.

When I first qualified, the hardest aspect of my job was the transition from dental nurse to clinician. I had loved my time as a nurse; being on the other side of the chair was quite daunting. However, the nursing team were wonderful and helped me through the first few weeks - gently reminding me not to do their job!

Before qualifying as an orthodontic therapist, I took the NEBDN post qualification Certificate in Oral Health Education and as part of this I visited local primary schools and Girl Guiding groups to give talks on oral health and healthy diets. I have since been asked by both groups to return and do the talk again and I am hoping this will become a regular presentation. I use the skills from the OHE course on a daily basis and the Orthodontic Nursing certificate provided an excellent base of knowledge prior to starting the Orthodontic Therapist Diploma.
Treasurer of the Peninsula Orthodontic Study Group and we run an annual study day on various orthodontic topics.

Depending on what after school clubs the kids have, I normally get home between 5.30$6 \mathrm{pm}$.

Living on Dartmoor we tend to try to take advantage of the great outdoors as much as possible by going for regular walks and I also try to go for a run once or twice a week. Weekends tend to be very busy running the kids to their various clubs and interests and trying to catch up with the housework. Whenever possible I like to try and catch up with my family and friends.

I do try to be careful with my family's oral health and enforce the 'sugar at mealtimes only' rule as much as possible. I enjoy cooking and I try to cook as many fresh meals as possible as this dramatically cuts down on excess salt and sugar. As a family we are fastidious toothbrushers - the children have grown up with my daily oral hygiene messages and neither I nor the girls have any fillings so

\title{
'I SEE MY PATIENTS EVERY SIX TO EIGHT WEEKS
}

\section{OVER A PERIOD OF ABOUT TWO YEARS AND}

\author{
DURING THAT TIME I FIND THAT I CAN
}

\section{REALLY BUILD A GREAT RELATIONSHIP WITH}

\section{THE PATIENT AND THEIR FAMILY.'}

In December, I passed the Peer Assessment Rating (PAR) calibration course in Cardiff and now carry out the PAR assessments for the department.

On a typical day, I try to be good and take a packed lunch with me, but I am sometimes tempted by chips from the hospital restaurant!

My one afternoon a week set aside for admin is when I try to fit in my online CPD. Many of my CPD requirements such as medical emergencies and disinfection and decontamination are met through the hospital's Mandatory Training programme. However, I am also a member of the Orthodontic National Group so I have automatic access to online CPD through ProDental and I often attend events set up by a local DCP Cluster Group.

For the past three years I have been the we must be doing something right!

This year we are saving for my eldest daughter to go on a school trip to China so we will stick to family days out during the summer rather than a holiday away. However, I am really looking forward to a weekend away with my girlfriends booked for May.

I love being an orthodontic therapist and don't want to ever stop doing clinical work. However, I am looking into taking some teaching qualifications in the future and hope to develop my career in this direction.

I always plan to go to bed earlier than I do, but generally it's around $10.30 \mathrm{pm}$.

Interview by Kate Quinlan 